\title{
$\therefore$ Efficacy of Fumigation in Management of Rodents in Rice Shellers in District Kaithal, India
}

\section{IJCRR}

Section: Healthcare

Sci. Journal Impact

Factor: 6.1 (2018)

ICV: 90.90 (2018)

\section{Priyanka Chaudhary}

Assistant Professor, Department of Zoology, DAV College (Lahore) Ambala city, India.

\section{ABSTRACT}

Introduction: Rodents are the most destructive among all the vertebrate pests. Rodents cause heavy losses to crops as well as to stored food grains. Rodents contaminate food with their urine, hair and droppings causing large scale infestation. Also, rodents are carriers and reservoirs of many diseases. Chemical control of rodents is the most practical, popular, effective and economic method.

Objective: This study was conducted in randomly selected different sized rice shellers in district Kaithal to devise an effective management strategy of rodents using chemical method.

Methods: In the present study, fumigation treatment was done through celphos (aluminium phosphide) tablets for the management of rodents in randomly selected different sized rice shellers in dist. Kaithal.

Results: A significant reduction in rodent populations by analysing through tracking markers census and bait intake census before and after fumigation. Significant control success was achieved resulting in $80.75 \%, 76.6 \%$ and $63.9 \%$ reduction in tracking marker census and $81.45(\mathrm{~g}), 72.97(\mathrm{~g})$ and $60.42(\mathrm{~g})$ reduction in bait intake $(\mathrm{g}) /$ bait box/ day in small, medium and small-sized rice shellers respectively.

Conclusion: Phosphine fumigation and venting can be achieved to disinfest grains stored in silo bags and the fumigant can be applied using widely available aluminium phosphide tablets in a method that must not contaminate the grain with residues.

Key Words: Stored food losses, Rodents, Management, Fumigation

\section{INTRODUCTION}

Rodents are the most destructive among all the vertebrate pests. Rodents have high reproductive potential, omnivorous feeding habits, quick sense of smell and extremely adaptive capabilities which helped them to establish worldwide in diverse habitats and climatic conditions and that too in large numbers. ${ }^{1,2}$ The tropical and sub-tropical climates are conducive to reproduction and population explosion of rodents. ${ }^{3}$

Today, rodents are a world-wide problem causing pre-harvest and post-harvest losses. ${ }^{4,5}$ Pre-harvest losses include the excavation and consumption of sown crop seeds, the cutting of tillers in cereal crops, the gnawing of tubers or fruits or internodes or canes etc. The post-harvest impact is caused during any period of storage in which damage is done by direct consumption due to gnawing and feeding and indirect damage by spoilage, contaminate with their urine or faeces. ${ }^{6}$
These notorious pests not only feed on grains but also contaminate 20 times more than what they consume with their droppings, urine, hair and even sometimes with their dead bodies. ${ }^{6}$ Rodents are also carriers and reservoirs of many diseases. $^{7}$

The losses of food grains are affected by the level of storage, distribution and consumption. ${ }^{8}$ A realistic estimate of the damage caused by rodents is difficult to assess due to the varied approaches and methods used in evaluating the damage in crops and storage. ${ }^{9}$ Hart (2001) has reported that overall losses of grains due to rodents in India were approximately $25 \%$ in pre-harvest and $25-30 \%$ in post-harvest situations, bringing the loss to at least US $\$ 5$ billion annually in stored food and seed grain in India. Keeping in view the economic losses caused by rodents to stored food grains, the present study has been conducted in randomly selected dif-

\section{Corresponding Author:}

Priyanka Chaudhary, Assistant Professor, Department of Zoology, DAV College (Lahore) Ambala city, India. Email: priyankakuk@rediffmail.com

ISSN: 2231-2196 (Print)

Received: 27.03 .2020
ISSN: 0975-5241 (Online)

Revised: 27.05 .2020
Accepted: 12.08 .2020 
ferent sized rice shellers in district Kaithal to devise an effective management strategy of rodents using chemical method.

\section{MATERIAL AND METHODS}

Haryana is self-sufficient in food grains production and one of the top contributors of food grains to the central pool. It contributes 40 to 45 lakh tonnes of food grains to the central pool which is the second largest. As far as the post-harvesting stage of grains is concerned, the state contributes $17.5 \%$ GDP of India.

Study Area: The present study has been conducted in district Kaithal of state of Haryana located between latitude $29^{\circ}$ $81^{\prime} \mathrm{N}$ and longitude $76^{\circ} 40^{\prime} \mathrm{E}$ (Fig. 1).

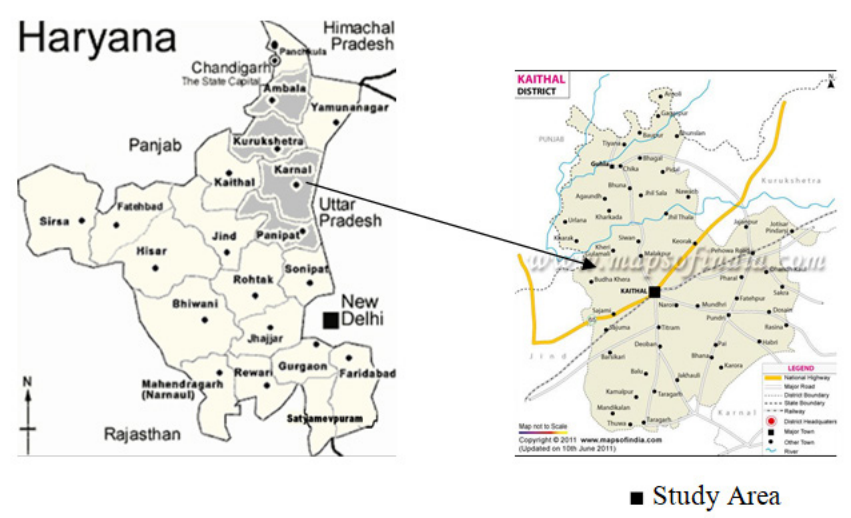

Figure 1: Map of state Haryana showing the study area.

\section{METHODOLOGY}

Chemical method was used for the management of rodents in three randomly selected different-sized rice shellers in district Kaithal (Photo 1). One large, one medium and one small-sized rice sheller was selected in the study area to evaluate the effectiveness of aluminium phosphide (fumigation) for the management of rodents. Fumigation technique was used in which celphos (aluminium phosphide) tablets were placed in required doses in meticulously tarpaulin-covered 50 stacks of paddy bags kept in the open yards of the rice shellers with the help of trained personnel (Photo 2, 3 and 4). The tarpaulin covers were removed after 24 or $48 \mathrm{hrs}$. and the dead rodents were collected and then buried.

Percent success was calculated through pre-treatment and post-treatment tracking markers census (\%) and bait intake census (g)/ bait box/ day. However, per cent success through pre-treatment and post-treatment bait intake census (g)/ bait box/ day and tracking marker census was calculated as:
Per cent success $=$ a-b $/ \mathrm{a} \times 100$

Where $\mathrm{a}=$ Pre-treatment bait intake census/ tracking markers census

$\mathrm{b}=$ Post-treatment bait intake census/ tracking markers census

\section{Tracking markers census}

Tracking markers census analysis was done following Parshad et al. ${ }^{10}$ to determine the level of rodent infestation before and after fumigation. Each tracking marker had $18 \mathrm{x}$ $18 \mathrm{~cm}$ white sheet with a $8 \times 8 \mathrm{~cm}$ central polythene sheet coated with a marking ink (Photo 5a). In each of the selected rice shellers, tracking markers were placed in the evening at strategic locations at a distance of about 10-15 feet along the walls keeping in mind where rodent activity was witnessed. Next morning, tracking markers were collected and the number of markers showing signs of rodent activity, i.e., paw marks or gnawing activity etc. was counted to determine the percentage of rodent activity (Photo 5b). Rodent activity was assessed using the formula following Parshad et al. ${ }^{10}$

Per cent rodent activity $=\frac{\text { Number of markers showing rodent activity }}{\text { Total number of markers placed }} \times 100$

\section{Bait Intake Census}

Bait intake census was done followed by Parshad et al. ${ }^{10}$ In bait intake census, bait boxes containing weighed baits were placed in the evening at strategic locations in each selected large, medium and small-sized rice shellers where rodent activity was remarkably noticed (Photo 6). Next morning, leftover baits were collected and weighed out to calculate bait intake census (g)/ bait box/ day. Bait intake census analysis has been done before fumigation (pretreatment) as well as after fumigation (post-treatment) to evaluate the effectiveness of fumigation technique for the management of rodents.

\section{RESULTS}

Chemical method was used for the management of rodents in randomly selected 3 different-sized rice shellers in district Kaithal. Efficacy of chemical method in the different-sized rice shellers was determined using tracking markers census analysis and bait-intake census methods. Pre control and post control census results revealed that in small-sized rice sheller, pre-control census through tracking markers census and bait intake (g) / bait box/ day was $72.5 \%$ and $15.10 \pm 1.34$ (g) / bait box/ day respectively and after fumigation the post control census through tracking markers census and bait intake (g) / bait box/ day was $12.5 \%$ and $2.80 \pm 1.23$ (g) / bait 
box/ day respectively. Per cent control success was achieved by fumigation treatment through celphos (aluminium phosphide) which revealed $80.75 \%$ reduction in tracking markers census and $81.45(\mathrm{~g})$ reduction in bait intake $(\mathrm{g}) /$ bait box/day in small-sized rice sheller.

Similarly, in medium-sized rice sheller, pre-control census through tracking markers census and bait intake (g) / bait box/day was $75 \%$ and $14.80 \pm 1.92(\mathrm{~g}) /$ bait box/ day respectively and after fumigation the post control census through tracking markers census and bait intake (g) / bait box/ day was $17.5 \%$ and $4.00 \pm 2.32(\mathrm{~g}) /$ bait box/ day respectively. The results revealed per cent reduction in tracking markers census by $76.66 \%$ and reduction in bait intake (g) / bait box/ day by $72.97(\mathrm{~g})$ in medium-sized rice sheller.

Also, in large-sized rice sheller, pre-control census through tracking markers census and bait intake (g) / bait box/ day was $69.33 \%$ and $13.04 \pm 2.18$ (g) / bait box/ day respectively and after fumigation the post control census through tracking markers census and bait intake (g) / bait box/ day was $25 \%$ and $5.17 \pm 2.96(\mathrm{~g}) /$ bait box/day respectively. Per cent control success was achieved showing per cent reduction in tracking markers census by $63.90 \%$ and reduction in bait intake $(\mathrm{g}) /$ bait box/day by $60.42(\mathrm{~g})$ in large-sized rice sheller (Table 1)

\section{DISCUSSION}

Chemical control of rodents is often considered as the most practical, economical and effective method of combating rodents in different situations as this method provides an immediate solution to the problem. ${ }^{11}$ Fumigation is considered an effective method of pest management in storage godowns, warehouses etc. ${ }^{12}$ It is the specialized process to exterminate the pest infestation in different agricultural commodities using various fumigants at various temperatures. A fumigant is a chemical which at required temperature and pressure can exist in the gaseous state in sufficient concentration for a time long enough to be lethal to a given pest organism. Presently, fumigation was done through celphos (aluminium phosphide) tablets that were placed in a tarpaulin-covered 50 stacks of paddy bags kept in the open yards in each of the selected different sized rice shellers and revealed a significant reduction in rodent populations. The aluminium phosphide liberates phosphine gas which when comes in the contact of moisture in the surrounding atmosphere and can be well applied while commodities are stored in the godowns before the commencement of export. However, the sources of fumigation depend on various factors such as airtightness, correct fumigant with the correct dose, correct diffusion, cor- rect penetration, proper monitoring, proper fumigation and protective equipment, the effect of temperature and humidity etc. During personal contacts with the rice sheller owners/ workers in the present study, it was found that most of the interviewees were ignorant about standard rodent control procedures in rice shellers and they used to hire trained personnel for the management of rodents.

In the present study, fumigation have been carried out in stacks of hoarded paddy bags kept in the open yards of rice shellers under gas proof covers as fumigation of big lot of food grains or other commodities is not possible in fumigation chambers as repeated fumigation in chambers involves laborious job and is time consuming. The stacks in larger lots are fumigated under gas proof covers (rubberized or plastic) in atmospheric conditions. These covers are so fabricated which retain the fumigant vapours for a sufficient time when placed over infested materials. This technique has widened the use of fumigants by making it possible to treat infested materials at their storage place. Silo or harvest bags are a relatively new form of temporary grain storage that is used to store a variety of agricultural goods such as wheat, silage and maize. ${ }^{13}$ Silo bags are loaded with grains and sealed at both ends. Guidelines for appropriate storage of various commodities have been developed based on initial grain conditions and management practices and models have been developed to predict heat and moisture transfer within silo bags filled with wheat. ${ }^{14}$ Successful phosphine fumigations have also been reported to be conducted within polyethene bags containing ground nuts and in a bag stack of rice under a polythene sheet. ${ }^{15,16}$ These fumigations were successful even though polyethene is known to be permeable to phosphine presumably because the rate of gas loss was sufficiently low for gas concentrations to be maintained at the required level for the fumigation period. ${ }^{17}$ The fumigant can be applied using widely available aluminium phosphide tablets in a way that will not contaminate the grain with residues.

In the present study, per cent control success was achieved by fumigation treatment through celphos (aluminium phosphide) which revealed $80.75 \%$ reduction in tracking markers census and $81.45(\mathrm{~g})$ reduction in bait intake $(\mathrm{g}) /$ bait box/ day in small-sized rice sheller. Similarly, in medium-sized rice sheller, per cent control success was achieved showing per cent reduction in tracking markers census by $76.66 \%$ and reduction in bait intake (g)/bait box/ day by 72.97 (g). Also, in large-sized rice sheller per cent control success after fumigation was achieved revealing per cent reduction in tracking markers census by $63.90 \%$ and reduction in bait intake $(\mathrm{g}) /$ bait box/ day by $60.42(\mathrm{~g})$. 
Table 1: Management through chemical control

\begin{tabular}{lcccccc} 
Rice shellers & \multicolumn{2}{c}{ Pre-control census } & \multicolumn{2}{c}{ Post-control census } & \multicolumn{2}{c}{$\%$ control success } \\
& $\begin{array}{c}\text { Tracking markers } \\
\text { census (\%) }\end{array}$ & $\begin{array}{c}\text { Bait intake } \\
\text { (g)/ bait } \\
\text { box/day }\end{array}$ & $\begin{array}{c}\text { Tracking } \\
\text { markers } \\
\text { census } \\
(\%)\end{array}$ & $\begin{array}{c}\text { Bait intake (g)/ } \\
\text { bait box/day }\end{array}$ & $\begin{array}{c}\text { Tracking mark- } \\
\text { ers census (\%) }\end{array}$ & $\begin{array}{c}\text { Bait intake }(\mathrm{g}) / \text { bait } \\
\text { box/day }\end{array}$ \\
Large sized & 69.33 & $13.04 \pm 2.18$ & 25 & $5.17 \pm 2.96$ & 63.90 & 60.42 \\
Medium sized & 75.00 & $14.80 \pm 1.92$ & 17.50 & $4.00 \pm 2.32$ & 76.66 & 72.97 \\
Small sized & 72.50 & $15.10 \pm 1.34$ & 12.50 & $2.80 \pm 1.23$ & 80.75 & 81.45 \\
\hline
\end{tabular}

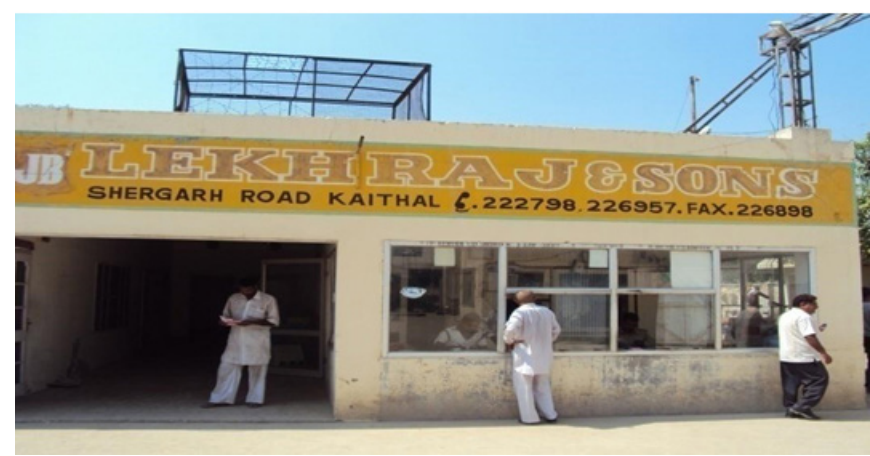

Photo 1: One of the studied rice shellers in district Kaithal.

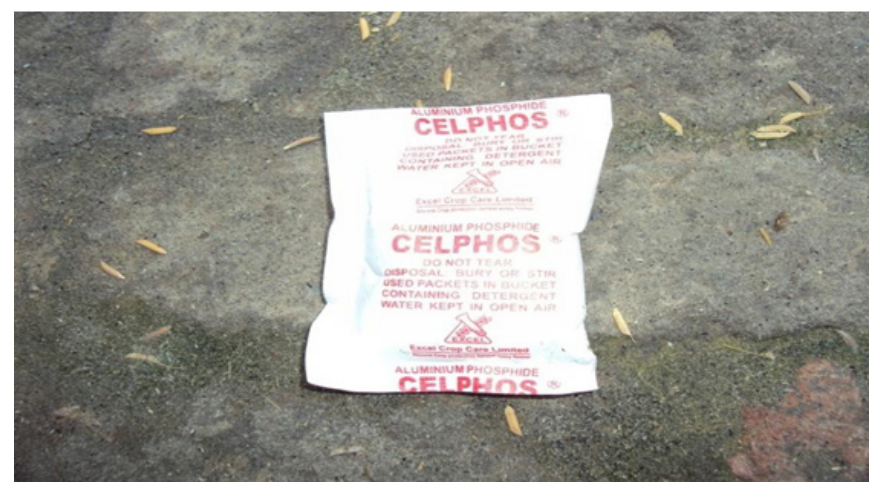

Photo 2: Celphos used as rodenticide by trained personnels for rodent management.

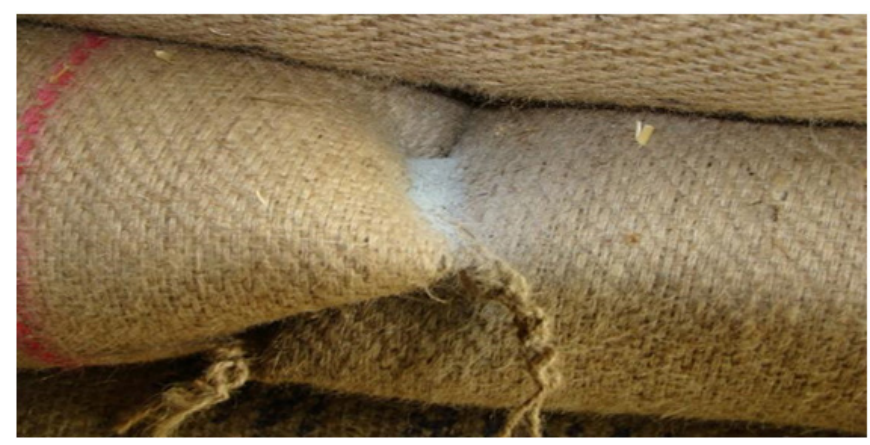

Photo 3: Fumigant placed by trained personnel in warehouse storage facilities.

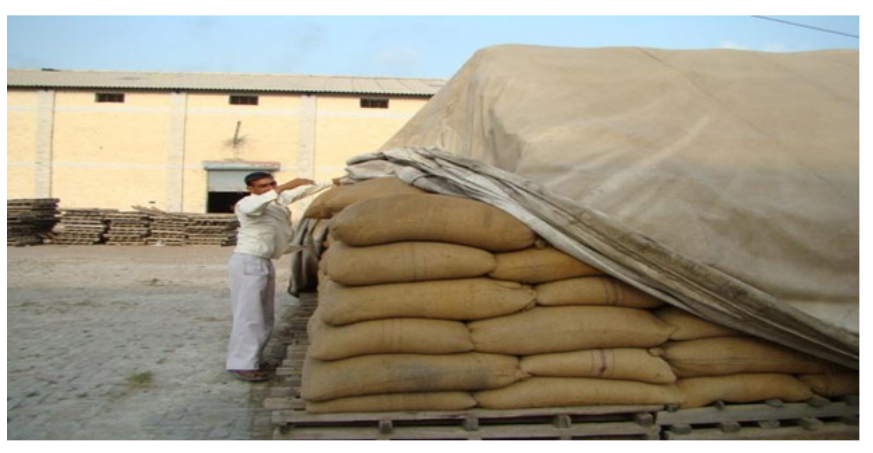

Photo 4: Covering of stacked gunny bags with tarpaulin covers in open yard of a rice sheller.

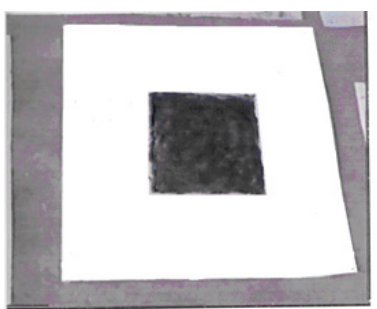

Photo 5(a):

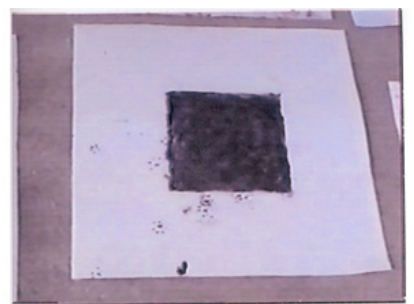

Photo 5(b):
Unused tracking marker. Tracking marker revealing rodent activity.

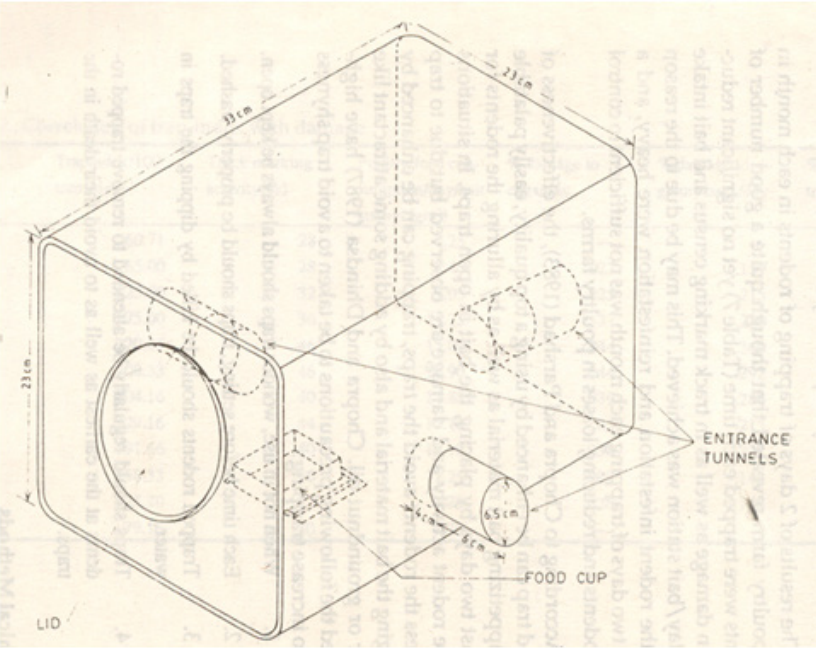

Photo 6: Bait box used at study site. 


\section{CONCLUSION}

Fumigation treatment was done for the management of rodents through celphos (aluminium phosphide) tablets that were placed in tarpaulin-covered 50 stacks of paddy bags kept in the open yards in each of the selected different sized rice shellers and revealed a significant reduction in rodent populations. The results of the treatment showed significant control success resulting in $80.75 \%, 76.66 \%$ and $63.90 \%$ reduction in tracking markers census and $81.45(\mathrm{~g}), 72.97(\mathrm{~g})$ and $60.42(\mathrm{~g})$ reduction in bait intake $(\mathrm{g}) /$ bait box/ day in small, medium and large-sized rice shellers respectively. So, phosphine fumigation and venting can be achieved to disinfest grains stored in silo bags and the fumigant can be applied using widely available aluminium phosphide tablets in a method that must not contaminate the grain with residues.

\section{ACKNOWLEDGEMENT}

I am extremely thankful to my research supervisor Dr. Girish Chopra for supervising this research work during my Ph.D. I am thankful to the owners of rice shellers in District Kaithal for their cooperation to carry out this research work at their respective facilities. I acknowledge the immense help received from the scholars whose articles are cited and included in references of this manuscript. I am also grateful to authors / editors / publishers of all those articles, journals and books from where the literature for this article has been reviewed and discussed.

\section{Financial Support: None}

Conflict of Interest: There is no conflict of interest in publishing this article.

\section{REFERENCES}

1. Chopra G, Kaur P, Guraya SS. Rodents Ecology, Biology and Control. R. Chand and Co. Publishers, New Delhi; 1996: 1-202.

2. Parshad VR. Rodent control in India. Int Pest Mgmt Rev 1999; 42: 97-126.
3. Parshad VR, Kaur P, Guraya SS. Reproductive cycles of mammals: Rodentia. In: Reproductive Cycles of Indian Vertebrates (Ed. SK Saidapur), New Delhi, Allied Publishers Limited; 1989:347-408.

4. Panti-May JA, Betancourt SH, Pina HR, Peralta SM. Abundance and population parameters of commensal rodents present in rural households in Yucatan, Mexico. Int Biodeter Biodegr 2012; 66: 77-81.

5. Bonnefoy X, Kampen H, Sweeney K. Public Health Significance of Urban Pests. WHO, Copenhagen; 2008.

6. Lathiya SB, Ahmed SM, Pervez A, Rizvi SWA. Food habits of rodents in grain godowns of Karachi, Pakistan. J Stored Prod Res 2008; 44: 41-46.

7. Meerburg BG, Kijlstra A. Role of rodents in transmission of Salmonella and Campylobacter. J Sci Food Agri 2007; 87: 27742781.

8. Rajendran TP, Tripathi RS, Dutta BC, Bora DK, Mohan Rao AMK. Rodent pest management in North east India. ICAR, CAZRI, Jodhpur. Tech Bull 2007; 15:2-3.

9. Singleton GR, Brown PR, Jacobs J. Ecologically-based rodent management-its effectiveness in cropping systems in Southeast Asia. Netherlands J Agri Sci 2004; 52: 163-171.

10. Parshad VR, Ahmad N, Chopra G. Deterioration of poultry house environment by rodents and their control. Int Biodet 1987;21(2): 29-46.

11. Yonas M, Welegerima K, Deckers S, Raes D, Makundi R, Leirs H. Farmers' perspectives of rodent damage and management from the highlands of Tigray, Northern Ethiopian. Crop Protection 2010; 29: 532-539.

12. Bell CH. Fumigation in the 21st century. Crop Protection 2000; 19: 563-569.

13. Darby JA, Caddick LP. Review of grain harvest bag technology under Australian conditions, CSIRO Entomology. Technical report No7. 2007.

14. Gaston A, Abalone R, Bartosik RE, Rodriguez JC. Mathematical modelling of heat and moisture transfer of wheat stored in plastic bags (silobags). Biosyst Engi 2009; 104: 71-85.

15. Proctor DL, Ashman F. The control of insects in exported Zambian groundnuts using phosphine and polyethylene lined sacks. J Stored Prod Res 1972; 8: 127-137.

16. Wang D, Collins P, Gao X. Optimising indoor phosphine fumigation of paddy rice bag-stacks under sheeting for control of resistant insects. J Stored Prod Res 2006; 42: 207-217.

17. Kashi KP, Muthu M, Majumder SK. Rapid evaluation of phosphine permeability through various flexible films and coated fabrics. Pesticide Sci 1977; 8: 492-496. 